\title{
DEVELOPMENT AND VALIDATION OF THE METHOD FOR SIMULTANEOUS DETERMINATION OF BENZYDAMINE HYDROCHLORIDE AND METHYLPARABEN IN BENZYDAMINE DOSAGE FORM BY GC
}

\author{
Vasyl Chornyi ${ }^{1}$, Victoria Georgiyants ${ }^{2}$ \\ "JSK “Farmak”, Ukraine \\ ${ }^{2}$ National Pharmaceutical University, Ukraine
}

\begin{abstract}
INTRODUCTION: Modern analytical chemistry is heading to the side of the "Green Chemistry" approach. The implementation of the current approach is in the development of fast analytical methods that combine the determination of several compounds with the utilization of methods that do not generate wastes of organic solvents.

AIM: The aim of the current work was to develop a method for the simultaneous determination of benzydamine hydrochloride (API) and methyl parahydroxybenzoate (preservative) in the dosage form.

MATERIALS AND METHODS: The development and validation of the proposed methodology were carried out.

RESULTS AND DISCUSSION: The validation parameters were determined; it was shown that the technique is robust, specific to determinable analytes.

CONCLUSION: The developed technique can be used in control laboratories for the simultaneous determination of benzydamine hydrochloride and methyl parahydroxybenzoate in the finished dosage form of benzydamine.
\end{abstract}

Keywords: benzydamine hydrochloride, methyl parahydroxybenzoate, gas chromatography, method validation, simultaneous determination

\author{
Address for correspondence: \\ Vasyl Chornyi \\ 101 Novobavarskiy Ave \\ 61019 Kharkiv \\ Ukraine \\ e-mail: vasylcherniy@gmail.com
}

Received: April 17, 2019

Accepted: June 5, 2019

\section{INTRODUCTION}

Benzydamine in the form of hydrochloride is an active pharmaceutical ingredient used for the dosage forms applied for the treatment of inflammatory diseases of the oral cavity. It also has analgesic and antipyretic properties $(1,2)$. Preparations based on benzydamine are used in postoperative therapy, as well as for the treatment of post-traumatic pains and effusions $(3,4)$. 
For oromucosal sprays, as for dosage forms of multiuse, it is necessary to use antimicrobial preservatives that inhibit the growth of microorganisms in the product (5). One of the most common preservatives for oral dosage forms is the methyl ester of parahydroxybenzoic acid (methylparaben) (6). Methylparaben shows activity against yeast and mold fungi, against gram-positive and gram-negative microorganisms (7).

High performance liquid chromatography (HPLC) determination of active substances and preservatives in pharmaceutical analysis has a dominant role due to the versatility of the method and the ability to determine the broad spectrum of non-volatile substances. However, the drawback of the method is the need for organic solvents and additives utilization, which are not only economically expensive but also harmful to the environment and the staff of control laboratories.

Compared with the HPLC method, gas chromatography has a number of undeniable advantages, which are the speed of the method, relatively low cost, as well as environmental impact. Thus, the use of inert carrier gases instead of toxic solvents, modified with salts of organic acids and bases, a smaller volume of the injected sample, the speed of analysis, and the use of highly effective capillary columns correlate with the need to comply with the principles of Green chemistry.

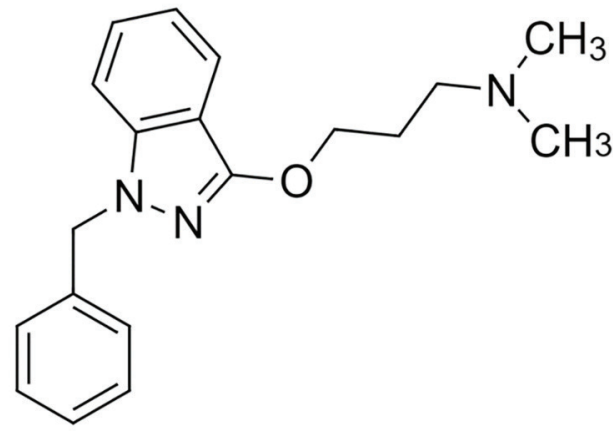

$\mathrm{HCl}$

Fig. 1. Structure of benzydamine hydrochloride

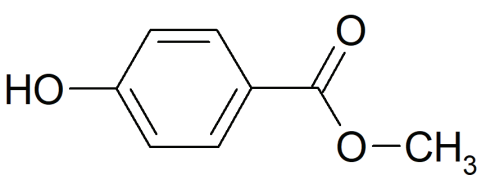

Fig. 2. Structure of methylparaben

\section{AIM}

The development of an express method for the determination of benzydamine and methylparaben in an oromucosal spray was an actual task, from the point of Green chemistry principles complement and the perspective of analytical control development at pharmaceutical enterprises.

\section{MATERIALS AND METHODS}

\section{Chemicals and Reagents}

Chloroform (GC grade) was supplied by Sigma Aldrich (Germany). Benzydamine hydrochloride reference standard, impurity A standard and methylparaben reference standards were purchased as per the British pharmacopeia standards.

\section{Apparatus and Software}

Chromatography was carried out using Agilent 7890 gas chromatograph with flame ionization detector, autosampler, and injector with split mode. Chemstation software was used for data acquisition.

\section{Chromatographic conditions}

$\diamond$ injector: temperature $300^{\circ} \mathrm{C}$, split 1:20;

$\diamond$ column: HP-5 (3.0 m x $0.32 \mathrm{~mm})$ with film thickness $0.25 \mu \mathrm{m}$;

$\diamond$ carrier gas: helium;

$\diamond$ detector: FID, temperature $300^{\circ} \mathrm{C}$;

$\diamond$ oven program: initial temperature of $220^{\circ} \mathrm{C}$ for 5 minutes, the gradient at a rate of $20^{\circ} \mathrm{C} / \mathrm{min}$ to a temperature of $270^{\circ} \mathrm{C}$ and an exposure time of 10 minutes;

$\diamond$ flow rate: $3 \mathrm{~mL} / \mathrm{min}$;

$\diamond$ injection volume: $1 \mu \mathrm{L}$.

\section{RESULTS}

\section{Method Development}

\subsection{Selection of Extraction Conditions and Inter-} nal Standard

The development of the methodology began with the selection of conditions for sample preparation of the substances. The Pharmacopoeia monograph describes the use of chloroform extraction, after the introduction of alkali into the test solution. However, this sample-preparation procedure is not suitable for the determination of methylparaben, since $\mathrm{pH}$ values of the solution greater than 8.0 lead to degradation of the molecule, which will lead to the impossibility of subsequent quantification of an an- 
alyte. In the process of the extraction conditions selection, it was found that the optimum $\mathrm{pH}$ of the medium is 6.0-7.0. Under these conditions, the degradation of the desired molecules does not occur, and the substances completely migrate to an organic solvent. Chloroform was used as the organic solvent. As an internal standard, a by-product of benzydamine hydrochloride synthesis - an impurity A was chosen, whose aqueous solution was prepared at a concentration equal to the concentration of benzydamine in the dosage form $(1.5 \mathrm{mg} / \mathrm{mL})$.

Thus, $5 \mathrm{~mL}$ of the test preparation was taken for the analysis, $5 \mathrm{~mL}$ of internal standard solution and $10 \mathrm{~mL}$ of chloroform were added. After intensive mixing, the solution was decanted and the organic layer was separated by a separatory funnel. The chloroform extract was subsequently used as the test solution.

\subsection{Selection of Concentrations of Test Solutions}

The initial concentrations of benzydamine hydrochloride and methylparaben in the drug were 1.5 and $1 \mathrm{mg} / \mathrm{mL}$, respectively. After sample preparation, in the final solution, the concentration of the analytes was 0.15 and $0.1 \mathrm{mg} / \mathrm{mL}$, which corresponds to a concentration of 0.15 and $0.1 \mu \mathrm{g} / \mu \mathrm{L}$ during chromatography. With such quantities, no overload of the column was observed; the peaks had an acceptable symmetry. Therefore, for the final method, such concentrations of substances in the test solution were chosen.

\subsection{Screening of the Stationary Phase}

The polarity of the stationary phase is a key factor for the successful separation of components in gas chromatography. When using columns with phase polarity, different from the polarity of the analytes, it can lead to peak broadening, poor retention, and unsatisfactory selectivity of the technique, which finally leads to incorrect results of quantification of the components being determined. Therefore, the choice of a stationary phase is a key factor in the analysis. Since benzydamine and methylparaben are high-boiling substances, when choosing a column, we considered selection of thermally stable phases. In the screening, phases of different polarity were used: HP-IINNOWAX (PEG), HP-FFAP (PET bound to nitroterephthalic acid), DB-624 (6\% cyano- propylphenyl / 94\% Dimethyl (poly) siloxane), and HP-5 (5\% Diphenyl / 95\% Dimethyl (poly) siloxane).

For separable analytes, the best selectivity and symmetry of the substances to be detected were observed when using the nonpolar HP-5 phase with a column geometry of $30 \mathrm{~m} \times 0.32 \mathrm{~mm} \times 0.25 \mu \mathrm{m}$.

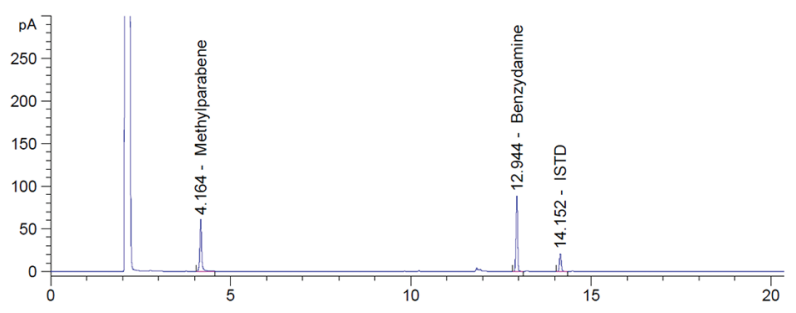

Fig. 3. Chromatogram of benzydamine and methylparaben on an HP-5 column

\subsection{Selecting the Parameters of the Injector}

To avoid column overloading, $1 \mu \mathrm{L}$ of the test solution was injected into the chromatograph. Taking into account the concentration of the analytes in the test solution, the 1:20 split was chosen. Regarding the high boiling temperatures of benzydamine and methylparaben $\left(474^{\circ} \mathrm{C}\right.$ and $265^{\circ} \mathrm{C}$, respectively), as well as a significant difference in the boiling point, it was necessary to select the temperature of the injector so that it allowed the analytes to evaporate evenly and at the same time without a discrimination of the sample. Three temperatures $\left(230^{\circ} \mathrm{C}, 270^{\circ} \mathrm{C}\right.$, and $300^{\circ} \mathrm{C}$ ) were tested. In this case, the first 2 options did not provide sufficient energy for the evaporation of benzydamine. At $300^{\circ} \mathrm{C}$, a sufficient reproducibility of the peak areas without degradation of the analytes was observed.

As an insert in the evaporator, a liner was used with the deactivated glass fiber placed therein.

1.5 Choice of the Chromatography Temperature Program

In case of a difference of boiling points of the analytes, as well as a difference in chemical properties, the isothermal mode of separation gave a significant difference in the retention times of benzydamine and methylparaben. During preliminary studies, it was established that methylparaben elutes at a temperature of $220^{\circ} \mathrm{C}$. At this temperature, the time of benzydamine retention is about 30 minutes. The optimal temperature for the elution of benzy- 
Development and Validation of the Method for Simultaneous Determination of Benzydamine Hydrochloride and Methylparaben...

damine was $270^{\circ} \mathrm{C}$. Therefore, during the develop- gram was set with an initial temperature of $220^{\circ} \mathrm{C}$ for ment of the temperature gradient, a thermostat pro-

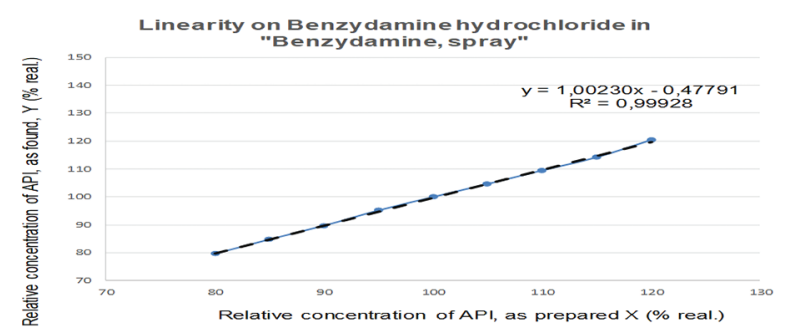

Fig. 4. Linearity of benzydamine hydrochloride 5 minutes and further increase at a rate of $20^{\circ} \mathrm{C} / \mathrm{min}$ to a temperature of $270^{\circ} \mathrm{C}$ and an exposure time of 10 minutes.

To prevent condensation of the sample in the detector, its temperature was set at $30^{\circ} \mathrm{C}$ higher than the final temperature of the thermostat.

\section{Validation of the GC Method}

The validation of the methodology was carried out for the next parameters:

$\diamond$ specificity;

Table 1. Linearity parameters for benzydamine hydrochloride

\begin{tabular}{lccc}
\hline Parameter & Symbol & Obtained Value & Acceptance Criteria \\
Correlation coefficient & $\mathrm{R}$ & 0.9996 & $\geq 0.99810$ \\
Intercept & $\mathrm{A}$ & 1.0228 & $\leq 2.6$ \\
Standard deviation & $\mathrm{S}_{\mathrm{A}}$ & $0.4779 \mathrm{I}$ & - \\
Slope & $\mathrm{B}$ & 1.0023 & - \\
\hline
\end{tabular}

Table 2. Results of accuracy for benzydamine hydrochloride

\begin{tabular}{|c|c|c|c|c|}
\hline Model Solutions & $\begin{array}{l}\text { Concentration of } \\
\text { Model Solution, } \\
\mathrm{mg} / \mathrm{mL}\end{array}$ & $\begin{array}{c}\text { Theoretical Concen- } \\
\text { tration, } \\
\mathrm{X}_{\mathrm{i}}=\left(\mathrm{c}_{\mathrm{i}} / \mathrm{c}_{\mathrm{RS}}\right)^{*} 100 \%\end{array}$ & $\begin{array}{l}\text { Found Concentra- } \\
\text { tion, } \\
Y_{\mathrm{i}}=\left(\mathrm{S}_{\mathrm{i}} / \mathrm{S}_{\mathrm{RS}}\right)^{\star} 100 \%\end{array}$ & $\begin{array}{c}\text { Found } \\
\text { Concentration/ } \\
\text { Theoretical } \\
\text { Concentration, \%, } \\
\mathrm{Z}_{\mathrm{i}}=\left(\mathrm{Y}_{\mathrm{i}} / \mathrm{X}_{\mathrm{i}}\right) \cdot 100 \%\end{array}$ \\
\hline M1 & 0.312 & 80.00 & 79.57 & 99.46 \\
\hline M2 & 0.332 & 85.00 & 84.75 & 99.71 \\
\hline M3 & 0.351 & 90.00 & 89.66 & 99.63 \\
\hline M4 & 0.371 & 95.00 & 95.15 & 100.16 \\
\hline M5 & 0.390 & 100.00 & 99.96 & 99.96 \\
\hline M6 & 0.410 & 105.00 & 104.62 & 99.63 \\
\hline M7 & 0.429 & 110.00 & 109.47 & 99.52 \\
\hline M8 & 0.449 & 115.00 & 114.18 & 99.29 \\
\hline M9 & 0.468 & 120.00 & 120.40 & 100.33 \\
\hline \multicolumn{4}{|l|}{ Average, Z, \% } & 99.79 \\
\hline \multicolumn{4}{|c|}{ Standard deviation, $\mathrm{SD}_{\mathrm{z}} \%$} & 0.34 \\
\hline \multicolumn{4}{|c|}{$\begin{array}{l}\text { Confidence interval for repeatability } \\
\Delta=\mathrm{t}(95 \%, 8) \cdot \mathrm{SD}_{\mathrm{z}}=1.8595 \cdot \mathrm{SD}_{\mathrm{z}} \%\end{array}$} & 0.63 \\
\hline \multicolumn{4}{|c|}{$\begin{array}{l}\text { Critical value for results } \\
\Delta \leq \max \Delta_{\mathrm{As}}=1.6 \%\end{array}$} & $\begin{array}{c}\text { Comply } \\
(0.63<1.6)\end{array}$ \\
\hline \multicolumn{4}{|c|}{ Systematic error $\delta=|\mathrm{Z}-100|, \%$} & 0.21 \\
\hline \multicolumn{4}{|c|}{ Criterion of insignificance of systematic error $\delta \leq \max \delta \%$} & $\begin{array}{c}\text { Comply } \\
(0.21<0.51)\end{array}$ \\
\hline
\end{tabular}


Vasyl Chornyi, Victoria Georgiyants

$\diamond$ linearity;

$\diamond$ precision;

$\diamond$ accuracy.

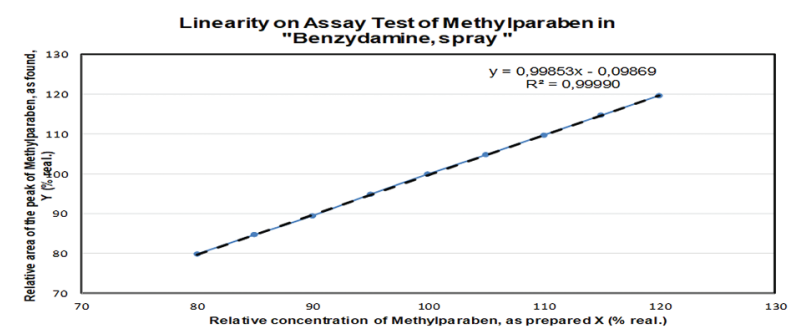

Fig. 5. Linearity of methylparaben
2.1. Evaluation of the Linearity of the Method for Benzydamine

For 9 model solutions of benzydamine hydrochloride, the least-squares method was used to determine the ratio of the amount found of benzydamine hydrochloride $(\mathrm{Y})$ on the given amount $(\mathrm{X})$, i.e. Dependence of the form $\mathrm{Y}=\mathrm{BX}+\mathrm{A}$.

Obtained results show that the method is linear for benzydamine hydrochloride.

\subsection{Evaluation of Accuracy for Benzydamine}

9 model solutions of benzydamine were injected in triplicate. The results are given in Table 2.

Table 3. Linearity parameters for methylparaben

\begin{tabular}{lccc}
\hline Parameter & Symbol & Obtained Value & Acceptance Criteria \\
Correlation coefficient & $\mathrm{R}$ & 0.9999 & $\geq 0.9924$ \\
Intercept & $\mathrm{A}$ & $0.0987 \mathrm{I}$ & $\leq 5.1$ \\
Standard deviation & $\mathrm{S}_{\mathrm{A}}$ & $0.4779 \mathrm{I}$ & - \\
Slope & $\mathrm{B}$ & 1.0023 & - \\
\hline
\end{tabular}

Table 4. Results of accuracy and repeatability for methylparaben

\begin{tabular}{|c|c|c|c|c|}
\hline Model Solutions & $\begin{array}{l}\text { Concentration of } \\
\text { Model Solution, } \\
\mathrm{mg} / \mathrm{mL}\end{array}$ & $\begin{array}{c}\text { Theoretical concen- } \\
\text { tration, } \\
\mathrm{X}_{\mathrm{i}}=\left(\mathrm{c}_{\mathrm{i}} / \mathrm{c}_{\mathrm{RS}}\right)^{\star} 100 \%\end{array}$ & $\begin{array}{l}\text { Found Concentra- } \\
\text { tion, } \\
Y_{i}=\left(S_{i} / S_{R S}\right)^{\star} 100 \%\end{array}$ & $\begin{array}{c}\text { Found } \\
\text { Concentration/ } \\
\text { Theoretical } \\
\text { Concentration, } \% \text {, } \\
\mathrm{Z}_{\mathrm{i}}=\left(\mathrm{Y}_{\mathrm{i}} / \mathrm{X}_{\mathrm{i}}\right) \cdot 100 \%\end{array}$ \\
\hline M1 & 99.84 & 80.00 & 79.87 & 99.84 \\
\hline M2 & 99.68 & 85.00 & 84.73 & 99.68 \\
\hline M3 & 99.43 & 90.00 & 89.49 & 99.43 \\
\hline M4 & 99.85 & 95.00 & 94.86 & 99.85 \\
\hline M5 & 99.96 & 100.00 & 99.96 & 99.96 \\
\hline M6 & 99.77 & 105.00 & 104.76 & 99.77 \\
\hline M7 & 99.77 & 110.00 & 109.74 & 99.77 \\
\hline M8 & 99.74 & 115.00 & 114.70 & 99.74 \\
\hline M9 & 99.73 & 120.00 & 119.68 & 99.73 \\
\hline \multicolumn{4}{|l|}{ Average, Z, \% } & 99.75 \\
\hline \multicolumn{4}{|c|}{ Standard deviation, $\mathrm{SD}_{\mathrm{z}} \%$} & 0.15 \\
\hline \multicolumn{4}{|c|}{$\begin{array}{l}\text { Confidence interval for repeatability } \\
\Delta=\mathrm{t}(95 \%, 8) \cdot \mathrm{SD}_{\mathrm{z}}=1.8595 \cdot \mathrm{SD}_{\mathrm{z}} \%\end{array}$} & 0.28 \\
\hline \multicolumn{4}{|c|}{$\begin{array}{l}\text { Critical value for results } \\
\Delta \leq \max \Delta_{\mathrm{As}}=1.6 \%\end{array}$} & $\begin{array}{c}\text { Comply } \\
(0.28<3.2)\end{array}$ \\
\hline \multicolumn{4}{|c|}{ Systematic error $\delta=|\mathrm{Z}-100|, \%$} & 0.25 \\
\hline \multicolumn{4}{|c|}{ Criterion of insignificance of systematic error $\delta \leq \max \delta \%$} & $\begin{array}{c}\text { Comply } \\
(0.25<1.02)\end{array}$ \\
\hline
\end{tabular}


Thus, the obtained results show sufficient accuracy and repeatability of the method.

\subsection{Evaluation of the Linearity for Methylparaben}

For 9 model solutions of methylparaben, the least-squares method was used to determine the ratio of the amount found of methylparaben $(\mathrm{Y})$ on the given amount $(\mathrm{X})$, i.e. Dependence of the form $\mathrm{Y}=$ $\mathrm{BX}+\mathrm{A}$.

Obtained results show that the method is linear for methylparaben.

2.4. Evaluation of Accuracy for Methylparaben

9 model solutions of methylparaben were injected in triplicate. The results are given in Table 4.
2.5. Evaluation of the Repeatability for Benzydamine and Methylparaben

The repeatability was evaluated by injection in triplicate of one reference solution and six test solutions, prepared from one sample of the preparation. The obtained experimental data are given in Table 5, 6 for the benzydamine hydrochloride and in Table 7, 8 for methylparaben.

\subsection{Specificity}

To show the specificity, a solvent and a placebo solution of the drug were injected. No interference was observed between the peaks of methylparaben, the internal standard, and benzydamine with peaks

Table 5. Results for repeatability for benzydamine hydrochloride

\begin{tabular}{l|c|c|c|}
\hline Name of the Solution & Average Area (S) & RSD S, (\%) & $\mathbf{X}, \mathbf{m g} / \mathbf{m L}$ \\
TS1 & 211.52 & 0.56 & 1.521 \\
TS2 & 223.15 & 0.68 & 1.512 \\
TS3 & 209.52 & 0.79 & 1.519 \\
TS4 & 215.85 & 0.44 & 1.525 \\
TS5 & 213.54 & 0.72 & 1.509 \\
TS6 & 217.85 & 0.65 & 1.51 \\
RS & 232.54 & 0.55 & - \\
Average & & & 0.43 \\
RSD, \% & & & \\
\hline
\end{tabular}

Table 6. Acceptance criteria

\begin{tabular}{lcccc} 
Parameter & Symbol & Analyte & Obtained Value & Acceptance Criteria \\
$\begin{array}{l}\text { Relative standard deviation of } \\
\text { six parallel injections, \% }\end{array}$ & RSD & $\begin{array}{c}\text { Benzydamine } \\
\text { hydrochloride }\end{array}$ & 0.43 & $\leq 1.4 \%$ \\
\hline \hline
\end{tabular}

Table 7. Results for repeatability for methylparabene

\begin{tabular}{lccc} 
Name of the Solution & Average Area (S) & RSD S, $(\%)$ & $\mathbf{X}, \mathbf{m g} / \mathrm{mL}$ \\
TS1 & 263.35 & 0.79 & 1.031 \\
TS2 & 255.22 & 0.81 & 1.023 \\
TS3 & 258.65 & 0.54 & 1.029 \\
TS4 & 254.19 & 0.64 & 1.042 \\
TS5 & 254.89 & 0.68 & 1.046 \\
TS6 & 253.85 & 0.75 & 1.039 \\
RS & 274.84 & 0.74 & - \\
Average & & & 1.035 \\
RSD, \% & & & 0.84 \\
\hline
\end{tabular}


Vasyl Chornyi, Victoria Georgiyants

Table 8. Acceptance criteria

\begin{tabular}{lcccc} 
Parameter & Symbol & Analyte & Obtained Value & Acceptance Criteria \\
$\begin{array}{l}\text { Relative standard deviation of six } \\
\text { parallel injections, \% }\end{array}$ & RSD & Methylparabene & 0.84 & $\leq 2.8 \%$ \\
\hline \hline
\end{tabular}

of placebo. The retention times of the analytes were compared with the retention times of the standard samples of benzydamine hydrochloride, methylparaben, and impurity A of benzydamine. In the chromatograms of the test solution, there was no interference between peaks of the analyzed components. Consequently, the method is specific to the defined analytes.

\section{DISCUSSION}

The aim of this study was to develop a methodology for the simultaneous determination of benzydamine hydrochloride and methylparaben in the finished dosage form of benzydamine hydrochloride with the implementation of the gas chromatography method.

The determination of benzydamine hydrochloride and methylparaben is described separately in literature and has not been studied simultaneously by far.

In routine control of benzydamine hydrochloride, chromatographic methods are used, mainly HPLC (8-10). A method for the spectrophotometric determination of benzydamine after the formation of the ion-pair complex with methyl orange has also been described (11). The monograph of the British Pharmacopeia describes the quantitative determination of benzydamine by gas chromatography using the extraction of an alkaline solution of benzydamine and packed columns with the OV-17 phase (12).

The determination of methylparaben in drug combinations also occurs predominantly by HPLC (13-15).

The gas chromatographic determination of methylparaben is described in combination with other preservatives in liquid products, as well as after derivatization with anhydrides of aliphatic acids with following micro extraction (16).

The basis of the method was taken from the monograph of the British Pharmacopeia for the determination of benzydamine in the finished dosage form. During the method development process, the optimal extraction conditions, the temperature of the injector, the detector, the flow velocity of the mobile phase, the stationary phase, the type of sample injection, and the temperature gradient were selected.

Validation of the method was carried out according to ICH Q2 guidance. All validated parameters were within the acceptance criteria. The method is linear for all compounds with a correlation coefficient of more than 0.999 .

\section{CONCLUSION}

This paper describes a method development, for assay of benzydamine hydrochloride and methylparaben in a dosage form of a spray, by gas chromatography on an HP- 5 capillary column (5\% diphenyl-95\% dimethylsiloxane) using chloroform extraction. The total chromatographic time was 17.5 minutes. The procedure is specific for the substances to be determined. Linearity, repeatability, and accuracy of the methodology are proved by validation tests. The procedure can be used in routine monitoring to determine benzydamine and methylparaben in preparations containing these components.

\section{REFERENCES}

1. Turnbull RS. Benzydamine hydrochloride (Tantum) in the management of oral inflammatory conditions. J Can Dent Assoc.1995;61(2):127-34.

2. Royal College of Anaesthesists. Guidelines for the use of non-steroidal antiinflammatory drugs in the perioperative period. London: RCA; 1998.

3. Kokki H. Nonsteroidal anti-inflammatory drugs for postoperative pain: A focus on children. Paediatr Drugs. 2003;5(2):103-23. doi: 10.2165/00128072-200305020-00004.

4. Baricevic D, Sosa S, Della Loggia R, Tubaro A, Simonovska B, Krasna A, et al. Topical anti-inflammatory activity of Salvia officinalis L. leaves: the relevance of ursolic acid. J Ethnopharmacol. 2001;75(2-3):125-32. doi: 10.1016/ s0378-8741(00)00396-2. 
5. USP <1111> Microbiological examination of nonsterile products: Acceptance criteria for pharmaceutical preparations and substances for pharmaceutical use. Current Version, The United States Pharmacopeial Convention, Rockville, MD. 2007.

6. Johnson R, Steer R, Methylparaben Monograph. In: Rowe RC, Sheskey PJ, Weller PJ, editors. Handbook of Pharmaceutical Excipients. 5 ed. Pharmaceutical Press; 2006. pp. 466-70.

7. Elder DP, Crowley PJ. Antimicrobial Preservatives. Part Two: Choosing a Preservative. American Pharmaceutical review [Internet]. 2012. Available from: https://www.americanpharmaceuticalreview. com/Featured-Articles/343543-Antimicrobial-Preservatives-Part-Two-Choosing-a-Preservative/

8. Carlucci G, Iuliani P, Di Federico L. Simultaneous determination of benzydamine hydrochloride and five impurities in an oral collutory as a pharmaceutical formulation by high-performance liquid chromatography. J Chromatogr Sci. 2010;48(10):854-9. doi: 10.1093/chromsci/48.10.854.

9. Catanese B, Lagana A, Marino A, Picollo R, Rotatori M. HPLC determination of benzydamine and its metabolite $\mathrm{N}$-oxide in plasma following oral administration or topical application in man, using fluorimetric detection. Pharmacol Res Commun.1986;18(4):385-403. doi: 10.1016/0031-6989(86)90091-3.

10. Cherniy VA, Gureeva SN, Georgiyants VA. Development and validation of alternative analytical method for determination of related substances of benzydamine hydrochloride in oral spray by high perfomance liquid chromatography. Pharm Sci Technol. 2016;1(5):25-33. doi: 10.11648 / j.pst.20160105.12.
11. El-Didamony AM. Spectrophotometric determination of benzydamine $\mathrm{HCl}$, levamisole $\mathrm{HCl}$ and mebeverine $\mathrm{HCl}$ through ion-pair complex formation with methyl orange. Spectrochim Acta A Mol Biomol Spectrosc. 2008;69(3):770-5. doi: 10.1016/j. saa.2007.04.032.

12. British Pharmacopeia. Vol. 3. H.M. Stationery Office; 1994. p.181.

13. Shabir GA. A new validated HPLC method for the simultaneous determination of 2-phenoxyethanol, methylparaben, ethylparaben and propylparaben in a pharmaceutical gel. Indian J Pharm Sci. 2010;72(4):421-5. doi: 10.4103/0250-474X.73906.

14. Kambale R, Singh SG, Singh S. Simultaneous determination of preservatives (methyl paraben and propyl paraben) in sucralfate suspension using high performance liquid chromatography. E-J Chem. 2010;8(1):340-346. doi: 10.1155 / 2011/360431.

15. Turabi ZM, Khatatbeh OA, Al-Abed DN. RP-HPLC Method development and validation for the simultaneous determination of mebendazole and the two preservatives methylparaben and propylparaben in pharmaceutical oral suspension dosage form. Int J Pharm Sci Drug Res. 2014;6(1):70-4.

16. Levchyk VM, Zui MF. Gas Chromatographic determination of parabens after derivatization and dispersive microextraction. Fr Ukr J Chem. 2015;3(2):72-9. doi: 10.17721/fujcV3I2P72-79. 